\title{
The National Physical Laboratory, Teddington INSPECTION BY THE GeNeral BoARD
}

$\mathrm{O}^{\mathrm{N}}$ June 25, the General Board of the National Physical Laboratory made its annual inspec. tion of the Laboratory. A large number of visitors were present, including members of scientific and technical institutions, Government departments and industrial organisations, and were received by Sir Frederick Gowland Hopkins, president of the Royal Society and chairman of the Board, the Right Hon. Lord Rayleigh, chairman of the Executive Committee, and the director of the Laboratory, Sir Joseph E. Petavel.

In the Physics Department of the Laboratory a number of problems connected with air conditioning of public buildings are being studied. Mention may be made of an examination of the water vapour absorptive properties of various classes of books, and of an investigation of the relationship between humidity and length for a number of hygroscopic substances, to ascertain their suitability for use in humidity-controlling apparatus. In the course of an investigation of the action of the wet and dry bulb hygrometer at low temperatures, a dew point apparatus has been developed for use as a standard of reference. In this, paraffin oil cooled by solid carbon dioxide circulates in a spiral path, attached to the back of a disc of chromium-plated silver, the temperature of which is measured by means of a thermoelement.

The apparatus devised for the determination of the ratio of the specific heats of carbon monoxide has been modified so that measurements of the velocity of sound can be made quickly at any one of several widely spaced frequencies. Electrically maintained quartz crystals are carried on a plate capable of rotation beneath the opening of a vertical furnace containing the gas under test. Each crystal gives a definite frequency so that the change of velocity with frequency can be determined at various temperatures of the gas.

For the measurement of the thermal conductivities of refractory materials, a test slab eighteen inches square and two inches thick is used. One face can be heated to $1,100^{\circ} \mathrm{C}$., and the heat transmitted through the central area is determined by means of a water-flow calorimeter.

In the Radiology Division the relation between crystalline structure and the magnetic, electrical and tensile properties of materials is under investigation by X-ray diffraction methods, special attention being given to the detection and measurement of internal strain. This strain results in a broadening of the diffraction lines, and the degree of broadening can be used as a measure of the amount of strain present. New equipment has been added to the Division for the study of materials by electron diffraction methods.

The measurement of gamma-ray dosage in röntgens is under investigation and experiments have been made with both 'free-air' and 'air-wall' chambers, the latter having walls composed of materials of effectively the same atomic number as air. The effect of wall thickness on the ionisation produced in 'airwall' chambers is being examined. A thick-walled chamber appears to indicate the dosage under conditions prevailing in deep-seated therapy, while a thin-walled chamber measures virtually the dose received at the surface.

In the Acoustics Laboratory considerable attention is being given to the problems of noise abatement and measurement. Investigations are being carried out on the sound-insulating properties against impact and air-borne noise of walls and floors of various designs. The use of absorbent materials in this connexion is being studied. For the measurement of noise, a portable acoustimeter has been developed in the Department. The instrument gives equal indications for notes of the same loudness, irrespective of pitch.

In the Optics Division a new type of colorimeter containing no rotating elements has been constructed. The light enters the mixing chamber through a condensing lens equipped with variable apertures containing the primary colour filters. Colour mixing is effected by the use of a small integrating sphere as a mixing chamber, the intensity of each primary stimulus being controlled by variation of the apertures.

In the Electric Standards Division of the Electricity Department consideration has been given to the construction of standard attenuators of calculable phase angle for the calibration of commercial attenuators at radio frequencies up to 1 mega-cycle per second. A combination of two of the laboratory residual inductance standards in the form of a potential divider can be used as an attenuator, and a number of units of this type have been constructed ranging in value from 1 decibel to 110 decibels.

An apparatus for the automatic comparison of frequencies by counting beats has been developed in the Division. The apparatus makes use of a system of relays which actuate, on one hand, a counter registering the number of beats produced by the two frequencies being compared, and, on the other hand, a counter registering seconds or fractions of a second down to one tenth of a second.

In the High Voltage Laboratory, oscillographic methods have been applied to the testing of lightning arresters. Experimental arrangements have been developed for determining the volt-ampere characteristics of arresters, the lag in their response to steep fronted overvoltages and their ability to interrupt the flow of current when the overvoltage has been disposed of. Records were shown illustrating the voltage acquired by a piece of apparatus with and without the arrester connected across it.

Research work is being carried out in the Electrotechnics Division of the Department on the alternating-current resistance of conductors for heavy currents. Formulæ have been developed for solid circular conductors giving close agreement with experimentally measured values. The problem of tubular conductors is now under examination.

An investigation is in progress in the Photometry Division to determine the illumination at which it becomes necessary to supplement daylight by 
artificial light, and automatic means have been developed for recording this in the case of a number of selected office lights. A solenoid included in each office lighting circuit operates the shutter of a cinecamera when the light is switched on. Each exposure records the date, the time of day, which office light is switched on, and the reading of a calibrated ammeter and rectifier photo-cell unit. This reading determines the illumination in the office. In the same Division research is being undertaken to determine the change of sensitivity of the eye during recovery from exposure to high brightness backgrounds or to isolated bright sources of light. The work has applications to the problem of the recovery of eye sensitivity from the glare of motor-car headlights.

In the Radio Department an exhaustive examination of the factors responsible for departure from frequency stability has revealed the necessity for high thermal and secular stability on the part of the inductance and capacitance. An inductance coil and variable condenser possessing extremely low temperature coefficients were exhibited; in these, use is made of differential expansion systems.

Attention has been given to the use of inverted diodes, split-anode triodes and magnetron oscillators as generators of very high-frequency oscillations. A demonstration was given of the generation, by a four segment magnetron, of ultra-short waves in a Lecher-wire system connected to the segments of the anode.

In the course of research on direction finding, a potentiometer method has been developed for the excitation of a rotating radio-beacon. The method utilises a dual potentiometer connecting an oscillator to two amplifiers which feed two pairs of aerials arranged at right-angles. The motion of the potentiometer contacts is such that the voltages applied to the two amplifiers vary sinusoidally and in opposite phases, producing a rotating field in the aerial system.

In an investigation into the nature and origin of atmospherics, oscillographic records have enabled the wave form and direction of individual atmospherics to be determined. Simultaneous records obtained at two different stations permit the place of origin of the atmospheric to be ascertained. Results obtained have shown that the recorded wave form of an atmospheric depends on the distance of the source producing the disturbance.

In the Metrology Department the standard leading screw lathe used for the correction of the pitches of lead screws has been entirely reconstructed. The traverse has now been extended to five feet and, by the introduction of change gears, screws having any English or metric right-handed pitches can be dealt with. Calibration of the reconstructed lathe has shown that its cumulative pitch is correct to within 0.0003 inch throughout its traverse.

New apparatus has been constructed for the direct testing of mercurial barometers at pressures varying from 2 in. to 34 in. of mercury, the pressure being accurately controlled by a specially designed barostat. The apparatus can accommodate five barometers for test in addition to the standard mercury barometer. A standard barometer has been constructed combining the principles of the Fortin, Newman and Kew barometers, so that instruments of all three types can be tested directly in the new apparatus.

The study of fatigue in relation to crystal structure has been continued in the Engineering Department and the effect of crystal orientation on fatigue strength is being examined for a number of single crystals of aluminium. Attention is also being given to the effect of intercrystalline boundaries on fatigue failure and tests are being made on specimens consisting of several crystals of aluminium. Specimens and results illustrating these two phases of the work were exhibited. For the determination of the fatigue strength of materials under combined alternating stresses, high-speed machines, in which different combinations of plane bending and torsion can be applied, have been constructed. Various plain and alloy steels and cast crankshaft materials are under examination.

Investigation is being made into the industrial applications of air injectors with reference to their use in maintaining air streams laden with granular matter. An experimental pneumatic conveyor has been constructed and experiments are being carried out to determine its performance.

The Department is investigating the principles underlying the design of satisfactory pipe-line joints capable of withstanding high temperatures and pressures. The work entails the study of the behaviour of flanged joints under pressure at air temperature, and at high temperatures, and measurements of bolt creep. The equipment permits tests to be made on 8 -in. pipe flanges at temperatures up to $1,000^{\circ} \mathrm{F}$. and at steam pressures up to $1,400 \mathrm{lb}$. per sq. inch.

A number of lubrication problems are receiving attention. Mention may be made of research on the aspect angle and attitude of a journal bearing under varying load, speed, clearance and temperature, and experiments on the effect of running in a clearance bearing at the seizing temperature of oils. Sensitive apparatus has been developed for measurement of the profile of bushes to determine the change of shape caused by running.

In the Metallurgy Department the production of iron of a high degree of purity has been achieved by the direct reduction of pure iron oxide in hydrogen. Specimens with a purity of the order of 99.99 per cent and of great softness and ductility were exhibited.

In view of the importance of oxide surface films in connexion with the problem of removing gases from molten metals, a systematic examination of the structure of such films is in progress by means of electron beam diffraction methods. The work has been extended to the study of oxide films formed on solid metals and alloys under atmospheric conditions and at high temperatures.

Considerable work is being carried out on the production of magnesium alloys, with the view of developing alloys stronger than those at present available for use at ordinary and at elevated temperatures. The microstructure, constitution and rolling and mechanical properties of various mag. nesium alloys are being investigated. The difficulty experienced in rolling and forging many of these alloys has been largely surmounted by slow pressing at high temperatures. A new experimental slowspeed rolling mill has been installed for use in breaking down the cast ingots.

In the Aerodynamics Department problems relating to the landing and take-off of aircraft are receiving attention. The work is of a two-fold character. The effect of landing flaps on stability near stalling incidence is being examined by means of the rolling balance. Measurements are made of the tendency of various wing sections, fitted with flaps and mounted on the balance, to accelerate or diminish rolling motion. The effect of proximity to the ground on the forces acting on an aeroplane is 
also under investigation. Systematic measurements are made of the lift, drag and pitching moment of models at various distances from the ground.

Research is being carried out on the effects of gusts on the stresses in aircraft, and apparatus has been designed for recording the changes in vertical wind velocity in a gust. The use of this apparatus in conjunction with a recording anemometer measuring the mean horizontal wind speed, gives sufficient information to permit the effect of the gust to be predicted.

The performance of a number of high-pitch airscrews covering a wide range of pitch/diameter ratio has been measured and the results have been correlated with modern airserew theory. Examination is now being made, by means of the hot spot method of flow photography, of the periodic flow through such airscrews, with the view of obtaining a direct experimental check of the basic assumptions of theory.

In the William Froude Laboratory, the effect of waves on ship resistance and propulsive efficiency together with the influence of hull form on this problem is under investigation. Demonstrations were given with a self-propelled model of a highspeed, twin-screw vessel. The speed, the propeller thrust, the amount of pitching and heaving, and the power required to drive the model are automatically recorded during its passage through rough water.

A number of model propellers made of a special aluminium alloy developed in the William Froude Laboratory were exhibited, together with apparatus for conducting tests with model propellers in open water.

\title{
The British Waterworks Association
}

\author{
AnNual Meeting
}

$\mathrm{T}$ HE annual meeting of the British Waterworks Association at Cambridge on June 26 was the occasion for a vigorous and outspoken presidential address by Prof. C. E. Inglis, who, after a brief but interesting account of the origin and early development of the University, reviewed the policy of successive Governments in the past in respect of water supply for the needs of the country, and made some caustic comments on the "futile process of appointing water Commissions and pigeon-holing their reports" which has been its chief characteristic. $\mathrm{He}$ added that he regretted to observe the reappearance of the "policy of procrastination which has blighted waterworks legislation for the past 60 years" in the recent announcement by the Minister of Health in the House of Commons that as a preliminary to water legislation of a general character, a Joint Committee of the House of Lords and the House of Commons was to be set up to report "on measures for the better conservation and organisation of water resources and supplies in England and Wales".

Four papers presented to the Conference were more or less technical in character. One on "Water Softening at Cambridge", jointly written by Dr. Suckling and Mr. Philip Porteous, described the particular nature of the water at Cambridge, and the method of softening adopted after full consideration of the relevant data. The Cambridge water, which is derived from the Chalk, a formation which outcrops in the southern half of the county, is stated to be "uniformly clear, bright and colourless" containing no iron or manganese in solution. "The total solids, magnesium content and permanent hardness are not unduly high and sodium salts are only sparingly present. The water is neutral in reaction, the content of carbonic acid is low and no corrosive tendency has been exhibited during many years of use." It is also of excellent organic and bacterial purity. Being convinced on these grounds that the desired degree of softening could be satisfactorily attained by either the lime or the base-exchange process, the final decision of the local water company in favour of the latter was made on the basis of financial and engineering considerations. Tabular analyses are given of the water before and after softening, the total hardness of the untreated water being $24 \cdot 0$ (temporary hardness, $17 \cdot 5$; permanent hardness, $6 \cdot 5$ ). After treatment and blending, the total hardness (entirely temporary) is $\mathbf{1 1 \cdot 5}$. The softened water sent into supply is described as "clear, bright, colourless, odourless and palatable". The watersoftening plant consists of six units, each of $9 \mathrm{ft}$. diameter, capable of delivering "zero hardness" water continuously at the rate of 16,000 gal. per hour for 10 hours, after which it is put out of commission for regeneration. Each cylinder contains about 10 tons (420 cu. ft.) of Doucil, a synthetic zeolite, and is supported on a 12-in. bed of graded gravel. The synthetic zeolite was chosen in comparison with natural zeolite on financial and engineering grounds as in the case of the process. The salt consumption for regeneration is guaranteed not to exceed a rate $5,600 \mathrm{lb}$. per million gallons of water softened to zero hardness.

The paper by Mr. Philip Ulyott on "Biological Research in Relation to Water Supply" was a brief statement of the results of modern investigation in the subject, and of the sequence of events connected with plant life in an aqueous environment. A lengthy paper, full of interest from the historical and engineering point of view, was contributed by $\mathbf{M r}$. H. C. Darby on "Windmill Drainage in the Bedford Level" in the southern part of the Fens. Writing in 1748, Thomas Neale states that "there are now no less than two hundred and fifty [windmills] in the Middle Level. In Whittlesey parish alone I was told by some of the principal inhabitants there are more than fifty mills and there are, I believe, as many in Donnington with its members. I myself, riding very lately from Ramsey to Holme, about six miles across the Fens, counted forty in my view." But, as Mr. Darby points out, the windmill was a "wayward co-operator at the mercy of wind and gale and frost and calm. It was never powerful and it never provided a satisfactory solution to the problem of clearing water from the drains." Finally, there was a paper of a financial and administrative character by Mr. T. Gr. Rose on "Modern Methods of Management Control". 